1. Interactions: Studies in Communication \& Culture

2. Volume 8 Number $2 \& 3$

3.

4.

5.

6.

NAEL JEBRIL

Bournemouth University

\title{
MATTHEW LOVELESS
}

Center for Research and Social Progress, European University

Institute

\section{Media audiences and media consumption during political transitions: The case of Egypt}

\section{ABSTRACT}

This article examines the role of new media in countries in transition. Using original survey data from Egypt (2012), we examine individuals' use of media to search for information following Egypt's participation in the Arab Spring. There are two provocative findings. One, different media satisfy informational searches at local, regional and international levels. And two, the profiles of 'new media' users are the most distinct among all mediums, matching the participants in non-traditional forms of political participation, namely urban-living males with education and access to income. Thus, in contrast to the technological determinism of some optimistic 'new media' supporters, in countries with low access levels to connectivity, this may suggest an analytical shift from medium to user to better facilitate our understanding of the role of new media in countries in transition.

\section{KEYWORDS}

mass media

political behaviour democratization Middle East/North Africa

Egypt

new media 


\section{Introduction}

How do citizens of transitional societies use media to make sense of potentially profound changes in the political environment? Are such media choices consistent across local, regional and international developments? Are all media searched in the same way by the same people? If not, which media and which media users - are most associated with participation in political actions?

To bring some evidence to bear on these questions, we use new survey data from Egypt in 2012 to examine the types of media choices citizens make to gather information about their local and larger worlds after such a change. Provocatively, we find that Egyptians are highly reliant on both television and social communication for gathering information/news about changes and developments in the Arab World. At the same time, there is no independent contribution of using the radio, newspapers or the Internet for this type of news search. However, when asked about gathering information about international events, all three alternative media outlets - radio, newspapers and the Internet (as well as social communication) - are conspicuously used while using television drops out.

These findings contribute to the larger literature in two ways. One, they again underscore that during periods of transition or turmoil, individuals searches for information are indications of their engagement with the transition process (in Central and Eastern Europe, see Loveless 2008). Thus, media are important facilitators to this process. Second, Egypt represents a low Internet penetration country - common among potentially transitional countries - and as such, we find very specific 'profiles' for Internet use (and weaker identities for other media' use). Thus, the context of transition matters to the role of 'new media' in transition; in contrast to the technological determinism of some optimistic'new media' supporters, in such countries, this may suggest an analytical shift from medium to user to better facilitate our understanding of the role of new media in countries in transition.

\section{Theory}

The theory of media dependency leads us to expect that citizens are more likely to turn to media as a source of reassurance and information in periods of political transition (Ball-Rokeach and DeFleur 1976). Such periods of transition or uncertainty undermine social, political and economic stability, motivating individuals to seek out resources that provide them with an explanation for - or understanding of - events. Media dependency also suggests that mass media are sources of reassurance and information. As such, '[...] rather than merely being heavier consumers, individuals are found to be more deliberate in their media consumption and this is a product of their informational demands' (Loveless 2008: 165, emphasis added). While such informational searching may not be not unexpected, here we are concerned with which media they choose for which search, particularly in the current context of the potentially revolutionary role of new media.

Two divergent perspectives seem to dominate this 'new media' debate in transitional contexts: cyber enthusiasts who emphasize the role of information and communications technologies and express optimism about their ability to empower people in non-democratic societies, and cyber sceptics who adopt a cautious position and suggest that the role attributed to new media can be rather exaggerated (for a detailed review of both approaches with regard to 
1. the Arab uprisings - see i.e. Comunello and Anzera 2012; Wolfsfeld et al. 2013;

2. Norris 2012). These polarized perspectives have generally formed the outline

3. of a significant body of research set to test the hypothesis that social media

4. had a significant impact on the outbreak of protests in the region.

5. A number of empirical studies have already concluded that the role of 6. social media in the Arab uprisings should not be overemphasized (see, e.g. 7. Norris 2012; Aday et al. 2012; Wolfsfeld et al. 2013), and a lack of consist8. ent correlation between social media use and successful mass protests is 9. well-documented (see Anderson 2011; Papic and Noonan 2011; Dajani 2012).

10. Furthermore, despite evidence that new media was used to organize and 11. sustain protests during the Arab uprisings, it is more difficult to demonstrate 12. a unique causal role (Aday et al. 2012). For example, the nature of the political 13. environment is seen to affect both the ability of citizens to gain access to social 14. media and their motivation to take to the streets (Wolfsfeld et al. 2013), i.e. as 15. a facilitator. A recent study has found that a host of factors such as grievances, 16. structural availability and network connections were more important than was 17. the use of new electronic communications media in distinguishing demon18. strators from sympathetic onlookers (Brym et al. 2014). It is thus suggested 19. that activists could have acquired their common identities and orientations 20. through a similar cohort experience and exposure to similar real-world prob21. lems (see Aday et al. 2012).

22.

23.

24.

25.

\section{New media and the Egyptian uprisings}

The Arab Spring has generated wide research interests among political science and communication scholars. Whereas the optimistic link between Internet and social media use about their power is understandable, e.g., scholars note that the most successful social movements in Egypt - including Kefaya, the April 6 Youth and We are all Khaled Said - were those using social media (Lim 2012: 231). However, the hypothesized role of Internet and new media in the uprisings is often counter balanced by evidence of a persistent gap between the young online political activists on the one hand and the broad offline Egyptian population on the other hand (see, e.g. Khamis et al. 2012). This is evident in the low rates of Internet penetration and usage, particularly in countries where protests and regime replacements took place (see Norris 2012; Wolfsfeld et al. 2013). On average, regional Internet penetration rates in the Arab World stood at around 28\% during the Arab uprisings (Dubai School of Government 2013). ${ }^{1}$ In Egypt, fixed broadband penetration remained also low at $2.2 \%$, whereas mobile broadband was seen as a strong substitute, accounting for approximately $80 \%$ of broadband subscriptions in the country (Arab Media Outlook 2012). ${ }^{2}$

Internet use in Egypt has been increasing rapidly, especially among young people between 20 and 30, also the fastest-growing population cohort in the nation (Abdulla 2007). This is not unique to Egypt as an international study conducted by Northwestern University in Qatar across eight Arab countries reported $82 \%$ of people under the age of 25 use the Internet, compared to only $37 \%$ of those over 45 . The study further revealed that only one in five Eyptians (22\%) uses the Internet and very few Egyptians (12\%) claim to have been online for ten years (Dennis et al. 2013). Thus those who do use the Internet appear to be concentrated among the young. According to the Arab Media Outlook Report (2012), amongst the 15-24 demographic, young Egyptians would rather give up watching TV than connecting to the Internet. 
In terms of social media, it is estimated that the Arab region had more 1. than 53 million active users of social networks in 2013 (Dubai School of 2. Government 2013). From the Arab Social Media Report (2013), we note that 3. the rate of growth in Facebook users in Q1 2011 across the whole Arab region 4. was $30 \%$, compared to just $18 \%$ in the same period the previous year. In addi- 5 . tion, Egypt constituted more than one quarter of total social network users in 6 . the Arab region and is reported to have the highest number of new Facebook 7 . users in the region since January 2013 with an increase of over 1.5 million 8 . users. Finally, about $80 \%$ of those aged less than 25 years old in Egypt used 9 . social networking sites at least four to five times per week. At the same time, 10. penetration of social media sites relative to the total population remained quite 11 . low. During the protests in January and February 2011, a Gallup poll showed 12. that only $8 \%$ of the Egyptian population got their news from Facebook or 13 . Twitter (Hellyer 2012). These combine to suggest a clear link between age and 14 . new media use.

\section{New media, mobilization and Generation Y: Just a correlation?}

Despite low penetration rates of Internet and thus social media networks in 19 many Arab countries, scholars have continued to justify the wide influence of 20 . new media use on the protests and political changes in the region. For exam- 21. ple, it has been argued that new media could have had an impact beyond 22 . their low adoption rates due to other factors, which include concentration of 23 . Internet and especially social media adoption among young people, a dispro- 24 . portionately large number of young adults in the population and the frequent 25 . sharing of information among social network members. Scholars also argue 26. that adoption of communication technologies, like other innovations, is typi- 27 . cally led by opinion leaders. In this way, social networks are seen to be essen- 28 . tial to innovation diffusion (see Kavanaugh et al. 2012).

At the same time, there is a demographic structure in the Arab region 30. favourable to political participation. It is estimated that more than $50 \%$ of the 31 . region's population belong to Generation Y or the Millennials (i.e. below the 32 . age of 25) (see Arab Media Outlook Report 2012). This pattern is well reflected 33. in Egypt, which is by far the most populous country in the Arab World with a 34 . population of around 80 million and median age of 24 during the Arab upris- 35 . ings (see Lim 2012). Over 60\% of Egypt's population is reported to be below 36. the age of 30, and young people aged 15-29 make up one-third of the coun- 37. try's total population. This demographic group is often relatively well educated 38 . compared to the total population, as mandatory primary education has led 39 . to significant education attainment in the past three decades (see Kavanaugh 40. et al. 2012). Many believe that the youthful composition of Arab populations 41. and their broad-based demographics more generally have played an impor- 42 . tant part in the protests (see Cottle 2011). Thus, an often assumptive link is 43. made between age, the ability to use new forms of communication and politi- 44 . cal action. 45.

Apart from the effects of new media use on political protests in the region, 46. the critical question of how and when new media consumption might facili- 47. tate political participation remains under researched. As noted by Wolfsfeld 48 . et al. (2013), if there is one single theme that runs through the literature on the 49 . potential impact of social media on collective action, it would be the varying 50 . role of social media in protests across the Arab region. It has therefore become 51. apparent that social media may not only refer to the information infrastructure 52 . 
1. and tools used to produce and distribute content, or to the actual digital 2. content produced, but also to the people and organizations that produce and 3. consume such content (see Howard and Parks 2012: 359).

Thus, we return to the central research question of this article. If individuals are more likely to use media in periods of change and/or transition, do different individuals search for information differently, consistent across local, regional and international developments? If not, do certain media - and thus certain media users - associate more strongly with significant political events? And if that is the case, the role of social media as a revolutionary medium may be less a matter of its technology than a matter of its mere (if timely) preference among revolutionaries.

\section{Methodology}

To investigate these questions, we use survey data from a nationally representative quantitative study on the media habits of Egyptian adults. The nationwide survey using face-to-face methodology was carried out by Gallup, Inc., under the Broadcasting Board of Governors' International Audience Research Program (IARP). ${ }^{3}$ The target population for this study is the civilian non-institutionalized adult (15 and older) population in Egypt. The total 15 and older population covered by this survey in Egypt is 56,994,000. The sampling frame consists of approximately 5000 primary sampling units in 22 governorates from the 2006 Egyptian Population Census, with updates in 2010. ${ }^{4}$ Weights were constructed to correct for disproportional ties in sampling and nonresponse and to ensure that the data are representative of the national population, based on age, gender and education. The questionnaire was developed in English and translated into Arabic by qualified translators. A sample $(N=$ 10) from the prospective respondents was selected to test the questionnaire. The fieldwork was conducted between 10 May and 19 May 2012. Interview times ranged from 15 minutes to 95 minutes. The average length of a successful interview was 37 minutes. A total of 2222 interviews were completed. The overall response rate is $92.6 \%$. Outright refusal accounted for $2.8 \%$ of non-interviews.

\section{Media use consumption}

Schmitt-Beck (2004) has suggested that different media consumption strategies are loaded with potentially and differentially influential information and depend on both the number of media used and the frequency with which each of them is used. Therefore, focussing on the entire information environment makes it possible to identify the relative importance of different mediums among individual media users. Debating the role of social media in the Arab Spring, several scholars also note that the role of new media in the Arab uprisings must be understood as part of a wider information arena in which new and old media form complex interrelationships (e.g. Aday et al. 2012) and propose a shift away from perspectives that isolate the Internet from other media (Aouragh and Alexander 2011).

In order to map individual media use patterns across different platforms and information sources, we proceed in two ways to build and compare 'profiles' of the 'average user' of different media. First, we look at 'media use' across traditional mass media, including television and radio as well as newer media such as the Internet and social media, more specifically (see Table 1).
3. The Broadcasting Board of Governors (BBG) commissioned Gallup to conduct the survey. All data belong to the BBG. The study was carried out in conformity with the standards of the ICC/ ESOMAR International Code on Market and Social Research (www. esomar.org/index.php/ codes-guidelines.html).

4. Using a systematic sampling method, that is equivalent to random sampling, 65 urban Primary Sampling Units (PSUs) and 85 rural PSUs were selected. On average, a PSU contains 200

households. The target number of respondents in each PSU is 10. As

of $2010,43 \%$ of the PSUs are classified as urban and $57 \%$ are classified as rural. $43 \%$ of the sample of 150 PSUs is drawn for urban PSUS and 58\% from rural PSUs in the 22 governorates. An oversample of 50 PSUs was obtained from the Cairo governorate. Border governorates of North and South

Sinai, Red Sea, New valley and Matrouh, representing roughly

$1.8 \%$ of the adult population, were excluded because of distance and cost considerations. Interviewers attempted interviews at each of the ten initial households, making up to three attempts to complete an interview 


\begin{tabular}{lllll}
\hline & Watch TV & Listen to radio & Use Internet & Y/N: Use social media \\
\hline Never & $20(0.9 \%)$ & $1299(60.7 \%)$ & $1593(74.6 \%)$ & No: $1699(79.8 \%)$ \\
More than 12 months & $6(0.3 \%)$ & $33(1.5 \%)$ & $11(0.5 \%)$ & Yes: $430(20.2 \%)$ \\
In last 12 months & $19(0.9 \%)$ & $28(1.3 \%)$ & $34(1.6 \%)$ & \\
In last 4 weeks & $49(2.3 \%)$ & $50(2.3 \%)$ & $78(3.6 \%)$ & \\
In last 7 days & $290(13.6 \%)$ & $219(10.2 \%)$ & $146(6.8 \%)$ & \\
Yesterday & $1755(82.1 \%)$ & $510(23.8 \%)$ & $273(12.8 \%)$ & \\
Total & $2139(100.0 \%)$ & $2139(100.0 \%)$ & $2135(100.0 \%)$ & $2129(100.0 \%)$ \\
\hline
\end{tabular}

Table 1: Distribution of general media consumption levels.

5. New media users are defined as those who used the Internet in the last four weeks or users of social media, and traditional media users are defined as those who used television or radio in the last four weeks and do not use the Internet.

6. The average new media user is 29 years old, while the average traditional media use is 38 years old
At first glance, it is hard not to notice the disparity in consumption patterns across television - where $82 \%$ reported watching as recently as yesterday - and both radio and the Internet in which nearly two-thirds and three-quarters of respondents report never using these media, respectively. What is additionally interesting about these broad usage responses is their low level of coordination. The correlation between radio and television use is essentially orthogonal: $r=0.01(p \leq 0.787, N=2139)$. Television consumption and Internet use are correlated at $r=0.08(p \leq 0.001, N=2135)$, and Internet and radio usage are coordinated at $r=0.10(p \leq 0.001, N=2135)$. While both latter correlation coefficients are statistically significant, 0.08 and 0.10 are nearly substantively negligible. Because using social media requires the use of the Internet, their association is much higher $\left(\chi^{2}=1900\right.$, $\left.\operatorname{prob}\left(\chi^{2}\right) \leq 0.001, N=2129\right)$.

While there is statistical significance between social media use and both radio and television consumption $\left(\chi^{2}=18.6\right.$, $\operatorname{prob}\left(\chi^{2}\right) \leq 0.002, N=2129$ and $\chi^{2}=11.3, \operatorname{prob}\left(\chi^{2}\right) \leq 0.045, N=2129$, respectively), we note that 374 of all the respondents $(87 \%)$ of the 430 respondents who said that they used social media had also reported watching television yesterday. Social media's relationship is less clear with radio as 228 (53\%) and $122(28 \%)$ respondents report having never listened to the radio or did so yesterday, respectively. In other words, other than the highly dependent activity of using the Internet to be active on social media, and the popularity of television as a family medium, which is quite evident in the Arab World (see i.e. Sakr 2002), media consumers are somehow medium loyal and less multi-medium users.

In order to construct a 'general-use' profile, academic research often tends 38 . to distinguish between users and non-users of new media (i.e. Internet and 39. social media). Looking at some of the basic differences between new and 40 . traditional media users in relation to the total adult population, ${ }^{5}$ we notice that 41 . the differences between traditional media users and the total population are 42 . minor. This is largely due to the fact that television is a universal medium. Few 43. notable findings are drawn from this comparison: first, a significant gender 44 . gap is present among new media users: males (65\%) vs females (35\%). The 45 . gap is both reversed and far less noticeable among traditional media users: 46. males (48\%) vs females (52\%). Second, almost half of new media users are 47. between 15 and 24 years old. The average new media user is 9 years younger 48 . than the traditional media user. ${ }^{6}$ Third, about four in ten traditional media 49. users only completed primary or less education (compares to 3\% among new 50 . media users). Not only low education is rare among new media users, but 51 . almost a third of them (30\%) completed university education, three times 52 . 
1. the percentage among traditional media users. Fourth, new media users have

2. $20 \%$ more urban residents than traditional media users. Finally, the economic

3. situation is slightly better for new media users. Only $6 \%$ find it very difficult

4. on present income and $21 \%$ live comfortably on present income compared

5. to $17 \%$ and $8 \%$ among traditional media users, respectively. Thus, the new

6. media population seems relatively advantaged compared to users of tradi-

7. tional media as well as the total adult population.

8. A 'general profile' would consist of individual attributes, e.g. gender, age,

9. income and education; individual propensities for media consumption, i.e.

10. interest in politics; and other structural variables that may frame individual

11. consumption choices, e.g. urban residence and the level of access infrastruc-

12. ture necessary for some forms of media. To determine the defining attributes,

13. we can regress the general-use variables on this set of variables to examine

14. profiles of media usage.

15. In Table 2, we can see that television watchers tend to have more media

16. technology at home, have higher levels of political interest, have more educa-

17. tion and interestingly, more likely to be unemployed. For radio, listeners

18. tend to be older, employed and have media technology at home. By contrast,

19. Internet and social media users share a number of commonalities: namely,

20. male, younger, more educated, urban dwellers, have higher income levels

21. and have the necessary technology at home. They differ in that while general

22. Internet users are less likely to be employed, social media users have higher

23. levels of political interest. Again, these profiles allow us to distinguish among

24. lower and higher levels of single medium use.

25. Internet and social media usage is more highly specified than television

26. and radio usage. That is, the ability to distinguish among those that use the

27. Internet/social media at different levels requires almost the full set of proposed

28.

29.

30.

31.

32.

33.

34.

35.

36.

37.

38.

39.

40.

41.

42.

43.

44.

45.

46.

47. No. of Obs

48. $t$ statistics in parentheses.

49. " $p<0.05$.

50. $\quad{ }^{* *} p<0.01$.

51. ${ }^{* * * *} p<0.001$.

52. Table 2: General media use.

\section{(1) Watch} TV

$-0.0405(-1.12)$

(2) Listen to radio

$0.000642(0.61)$

$-0.151(-1.38)$

$0.0134^{*}(2.18)$

$0.0121^{* * *}(3.81)$

$-0.0945^{* *}(-2.58)$

$-0.0383^{*}(-2.06)$

$0.301^{* *}(2.72)$

$-0.0219(-0.67)$

$0.00495(0.05)$

0.0207 (1.12)

$-0.0611(-1.10)$

$0.0521^{* * *}(4.55)$

$0.469^{* * *}(13.55)$

(3) Use Internet

$0.125^{* * *}(7.52)$

0.0674 (1.34)

$0.523^{* * *}(7.07)$

$-0.350(-1.52)$

$-0.0305^{* * *}(-14.13)$

$0.0782^{* * *}(6.21)$

$-0.245^{* *}(-3.27)$

$0.226^{* * *}(3.39)$

$0.129^{* * *}(3.41)$

$0.534^{* * *}(22.74)$

$4.057^{* * *}(53.21)$

0.1102

0.0259 (0.76)

0.0674

(1)

$-0.857^{* * *}(-5.48)$

$-6.833^{* * *}(-13.18)$

0.4376

2118

2118

2114
$0.924^{* * *}(14.66)$

$0.234^{*}(2.28)$

(4) $\mathrm{Y} / \mathrm{N}$ : Use social media

$1.080^{* * *}(6.16)$

$0.309^{* * *}(8.18)$

$-0.187(-1.06)$

$0.335^{*}(1.99)$

$0.246^{*}(2.48)$

(2)

0.4693

2108 
7. The rest ranged fairly evenly between 0.05 and 0.28 . individual attributes, propensities and structural variables: namely, younger, 1 . more educated, urban dwelling, high-income males that have technology at 2 . home. Only in the case of Internet is unemployment negatively related to use. 3. This suggests that there are fewer meaningful dimensions across which to 4 . distinguish high-level from low-level television viewers and radio listeners. In 5 . other words, Internet/social media users are a specific and easily identifiable 6 . demographic.

\section{Media for news}

The profiles of various media consumption patterns are interesting, and here we want to expand on this to look at the choices people make in not merely using a medium but specifically looking for news. Respondents were asked to answer the following:

People get news from many different sources. For each one of the sources I mention, please tell me whether you use that source to get news most days per week, at least once a week, at least once a month, less than once a month, or never.

They are then given the choices of $\mathrm{TV}$, radio, newspapers, the Internet and friends/family.

In Table 3, the consumption of media for specific ends, i.e. news, reflects the overall pattern seen above (see Tables 1 and 2). Television is by far the dominant medium with friends/family being the second most relied upon 'news outlet' followed by radio, newspapers and the Internet. Also similar to the general media use patterns, there is little cross-medium coordination in media use. The highest correlation between these news outlets is between newspaper and the Internet at $r=0.33(p \leq 0.001, N=2136){ }^{7}$

Of those who do use the Internet, the survey also included a question that asks 'In the last 7 days, which of the following activities have you used the Internet for?' $(N=419): 80 \%$ of Internet users mentioned using the Internet to find out the latest news and $68.5 \%$ said they used the Internet to find information online about a specific topic. Thus, Internet use is dominated by information-seeking behaviour. The communication purpose came third with $57.5 \%$ say they use Internet to send or receive e-mail. Internet users were further asked 'Which of the following services have you used in the past 7 days for social networking?' $(N=430)$ : Facebook $(80 \%)$, Twitter $(14 \%)$, YouTube $(55 \%)$ and Google + (79\%). When asked'what are up to three websites you use most 
1. frequently to get news and information?' $(N=531), 26 \%$ mentioned Google

2. and only $23 \%$ mentioned Facebook. Yahoo and YouTube were both mentioned

3 . and equally scored only $2 \%$. Facebook is thus mainly used for social network-

4. ing. In addition, 33\% reported accessing the Internet in English when asked

5. 'Do you access the Internet in any of the following languages?' Understanding

6. a second language indicates opportunities for exposure to wider information

7. sources among new media users.

8. If we again look at news choice consumption through the lens of indi-

9. vidual profiles, we find a familiar if even strong suggestion that television is a

10. universal medium (and to some degree both radio and newspapers) and the

11. Internet (and related technology) has more highly specified but information-

12. seeking consumers (see Table 4).

13. In terms of individual attributes, males use both newspapers and the

14. Internet; the youth tend to use the radio and newspapers less but both the

15. Internet and friends and family. Education is positively correlated with all but

16. television and radio. Except for newspapers, urban residence has a positive

17. effect on media choices. Finally, income has a positive effect on only Internet

18. use and family/friends. Unsurprisingly, higher levels of political interest and

19. having technology at home (except television) are positively related to news

20. searches across all media.

21. The intensity of media choices seems to respond to both individual attrib-

22. utes and structural differences. In addition, in lieu of a direct test, we have

23.

24.

25.

26.

27.

28.

29.

30.

31.

32.

33.

34.

35.

36.

48. $t$ statistics in parentheses.

49. ${ }^{*} p<0.05$

50. ${ }^{* *} p<0.01$.

51. ${ }^{* * * *} p<0.001$.

52. Table 4: Media use for news. 
8. Response categories include the following: very interested, somewhat interested, not very interested or not at all interested.

9. Response categories include the following every hour or more, two to three times a day, once a day, two to three times a week once a week or less than once a week.

10. $48 \%$ of new media users reported accessing news more than daily compared to $38 \%$ of traditional media users

11. Response categories include the following daily or most days per week, at least once a week, at least once a month, less than once a month or never.

12. $88 \%$ of new media users reported discussing or sharing news compared to $74 \%$ of traditional media users. seen clear variation in media choice 'profiles'. That is, newer media tend to be 1 . predominantly used by a startlingly precise profile user, namely, the urban, 2 . educated male in a higher income family (and the incumbent structural 3. advantages that confers). Older mass media, traditional print and broadcast 4 . media, on the other hand, have less clear boundaries between users. This is 5 . not a limitation to our understanding suggesting instead a wider, more demo- 6 . graphically diverse and dispersed audience.

Respondents were further asked to state their level of interest with a 8 . number of topics including political news, business news and the economy, 9 . health care, arts and culture, sports, women's issues, science and technology, 10. environment issues and education. ${ }^{8}$ The descriptive analysis of the data shows 11. that $72 \%$ of new media users were very interested in political news compared 12 . to only $57 \%$ of traditional media users. As far as interest in other topics is 13 . concerned, new media users were at least as interested or more interested 14 . than traditional media users (also the general population) in every issue. This 15 . shows that interest in politics among new media users is not unique. New 16. media users are generally interested publics.

\section{Media use and interest in politics}

The above analysis is descriptive and not meant to imply underlying causal 21 . relationships or promote theoretical develops; it is an attempt to think 22 . about how media are used to collect information about politics - particularly 23 . comparing new media with traditional media. Above, we have looked at vari- 24 . ous profiles of media choices. What we are interested next is to bring some 25 . further evidence to more fully describe the media topography of the region at 26 . this time. What media choices are made to make sense of the world around these 27. users? How do these citizens find information about their local and larger worlds?

To investigate this, we want to examine how media choices and preferences for political information (in the context of individuals' levels of interest in politics) shape information gathering. To do so, we have added two new variables to this analysis. The first is meant to capture specific people who respond that they check in on news more often ('Now I'd like you to think about news for a moment. In general, how often do you access any type of news? By any type, I mean news on radio, TV, Internet, newspapers, etc?').9 This soaks up overt and residual 'interest' levels. We call these people, 'news hounds' ${ }^{10}$

Second, as we have seen above, family and friend networks constitute the second largest news source in the region. This is expected as in low penetration countries, social communications is the most common form of news gathering. For example, in Brazil during the 2002 presidential election, political discussion within social networks best explained individuals' change of preferences throughout the campaign (Baker et al. 2006). To control for this, we include a social communication variable that can serve not only as an indicator of familial or friendly political conversation ('How often do you discuss or share news about current events with other people?' $)^{11}$ but also local elite cues and 'leader' roles that often serve as direct competitors to media as source of information. ${ }^{12}$

In doing so, we are including media choices and preferences for political 49 . information as well as political interest. Thus, we are moving beyond descrip- 50 . tion and towards explanation of media choices. To motivate media engage- 51. ment, we include several new dependent variables that incentivise media 52 . 
1. choices. The first set of two asks respondents, 'Now I would like to ask you 2. some questions about media coverage of changes in the Arab world. How inter3. ested are you in information about these issues?' (emphasis added). ${ }^{13}$ Second, 4. respondents were asked, 'How interested are you in the following types of 5. coverage of the protests and political changes in the Arab world? Tell me if 6. you are very interested, somewhat interested, not very interested, or not at all 7. interested'. We use the 'breaking news' type of coverage to assess searching 8. for information quickly (or primary media choice). The other set of questions 9. asks, 'How interested are you in each of the following types of news? Tell me 10. if you are very interested, somewhat interested, not very interested, or not at 11. all interested?' Respondents respond to three levels of news, domestic, Arab 12. World and international news. New media users were generally more inter13. ested than traditional media users across all news levels.

14. To further this investigation, we include the variables from above that ask 15. respondents about their level of use of various media when looking for news. 16. Here, the socio-demographic attributes are included as controls for these 17. media choices as are the new 'news hound' (preferences for political informa18. tion) and social communication variables.

19. In Table 5, for both interest in changes in the Arab World and 'breaking 20. news', searches are strongly coordinated with higher levels of television news 21. searching. None of the other media variables reached statistical significance. 22.

23.

24.

25.

26.

27.

28.

29.

30.

31.

32.

33.

34.

35.

36.

37.

38.

39.

40.

41.

42.

43.

44.

45.

46.

47. No. of Obs

48. $t$ statistics in parentheses.

49. ${ }^{*} p<0.05$.

50. ${ }^{* *} p<0.01$

51. ${ }^{* * *} p<0.001$

52. Table 5: Interest in changes and breaking news in the Arab World.
13. Response categories include the following. very interested somewhat interested, not very interested or not at all interested 


\begin{tabular}{llll}
\hline & $\begin{array}{l}\text { (1) Interest: } \\
\text { domestic } \\
\text { news }\end{array}$ & $\begin{array}{l}\text { (2) Interest: } \\
\text { Arab World } \\
\text { news }\end{array}$ & $\begin{array}{l}\text { (3) Interest: } \\
\text { international } \\
\text { news }\end{array}$ \\
\hline TV for news & $0.130^{* * *}(7.46)$ & $0.0793^{* *}(2.89)$ & $0.0195(0.71)$ \\
Radio for news & $0.00100(0.12)$ & $0.00312(0.24)$ & $0.0293^{*}(2.23)$ \\
NPs for news & $0.00734(0.76)$ & $0.0286(1.87)$ & $0.0707^{* * *}(4.65)$ \\
Internet for news & $-0.00805(-0.75)$ & $-0.00116(-0.07)$ & $0.0537^{* *}(3.17)$ \\
News hound & $0.146^{* * *}(11.39)$ & $0.162^{* * *}(7.99)$ & $0.121^{* * *}(5.99)$ \\
Social communicator & $0.0861^{* * *}(7.33)$ & $0.117^{* * *}(6.33)$ & $0.0478^{* * *}(2.58)$ \\
Political interest & $0.232^{* * *}(13.92)$ & $0.153^{* * *}(5.82)$ & $0.107^{* * *}(4.07)$ \\
Gender: male & $0.0209(0.67)$ & $0.0830(1.69)$ & $0.202^{* * *}(4.13)$ \\
Age & $0.000784(0.84)$ & $0.00194(1.32)$ & $0.00192(1.30)$ \\
Education level & $0.0194^{* * *}(3.55)$ & $0.0452^{* * *}(5.23)$ & $0.0401^{* * *}(4.65)$ \\
Have paid job & $-0.0119(-0.38)$ & $-0.0205(-0.42)$ & $-0.106^{*}(-2.16)$ \\
Residence: urban & $-0.0155(-0.56)$ & $-0.155^{* * *}(-3.55)$ & $0.0149(0.34)$ \\
4 cat: income & $-0.0117(-0.75)$ & $-0.00960(-0.39)$ & $0.0293(1.19)$ \\
Technology at home & $-0.00153(-0.14)$ & $0.0498^{* *}(2.91)$ & $0.00274(0.16)$ \\
Constant & $1.169^{* * *}(13.14)$ & $0.0292(0.21)$ & $0.0938(0.67)$ \\
Adj. R2 & 0.4406 & 0.2762 & 0.2162 \\
No. of Obs & 2086 & 2083 & 2083 \\
\hline
\end{tabular}

$t$ statistics in parentheses.

${ }^{*} p<0.05$.

${ }^{* *} p<0.01$.

${ }^{* * * *} p<0.001$.

Table 6: Interest in local, regional or international news. 2. 3. 4. 5. 6. 7. 8. 9. 10. 11. 12. 13. 14. 15. 16. 17. 18. 19. 20. 21. 22. 23. 24. 25. 26. 27. 28. 29. 30. 31. 32.

In addition, we see that'news hounds', social communicators and those with 33 . higher levels of political interest are positively related to attention to both 34 . changes in the Arab World and 'breaking news' type of coverage of political 35. changes.

The final set of questions is used to distinguish between not only types 37. but levels of news, i.e. local, regional and international (see Table 6). Similar to 38 . above, we find that that 'news hounds', social communicators and those with 39 . higher levels of political interest are positively related to attention to all levels 40 . of news. The use of television news again dominates local and regional inter- 41 . est, however fails to reach significance for international news. This is inter- 42 . esting as the alternative three - radio, newspaper and the Internet - are all 43. statistically significant and positively correlated with interest in international 44 . news. $\quad 45$. 45.

47.

Discussion

48.

This analysis points towards a number of important potential findings. Most 49 . importantly, there is clear evidence that media users are largely medium loyal, 50. such that, Egyptians are highly reliant on television and social communication 51 . 
1. for gathering information/news about changes and developments in the Arab 2. World. We, however, do not claim that Egyptians are inherently platform loyal 3. as penetration/accessibility rates for some media are low.

4. New media audiences on the other hand are easily and specifically iden5. tifiable (namely, male, younger, more educated, urban dwellers, have higher 6. income levels and have the necessary technology at home). They are also 7. interested publics who not only are demographically different from the aver8. age media user but also tend to show distinct patterns of media behaviour. ${ }^{14}$ 9. This provides indirect evidence for the linkage between social media and 10. political change. More interestingly, it indicates that context is important 11. for understanding this relationship. In Egypt, the reference to the role of 12. new media in politics is plausible largely because it describes and encom13. passes a specific and identifiable segment of the population. In countries 14. with high Internet penetration, referring to new media usage may be less 15. meaningful as far as politics is concerned. Similarly, low Internet penetration 16. rates should not be seen as a reason to dismiss the role of social media in 17. politics. The adoption of new media in Egypt not only does describe 'plat18. form usage' but also refers to the multiple unique characteristics of its users. 19. Thus, in countries where new media audiences are wider and demographi20. cally diverse, focus on users becomes less relevant for understanding new 21. media effects on politics while content and consumption behaviour grow 22. more important.

23.

While medium use moves in a coordinated manner with interest in news, medium choice (particularly new media) is largely influenced by a host of individual and structural variables. This has two implications: first, this suggests that new media use in Egypt, and perhaps accessibly as well, can partially be viewed as a 'choice'. Second, this undermines support for technological deterministic approaches to new media influences on politics in Egypt as a low Internet penetration country.

However, in terms of overall media use in periods of transition, individuals' medium choices are clearly related to various interests in domestic, regional or international news suggesting some coordination. For example, television, with its wider, more demographically diverse and dispersed audience, is significantly related to interest in local and regional news. This mirrors previous research findings showing television networks are the most important source of general news, and news about the uprisings, in Tunisia and Egypt (see Norris 2012). This is more broadly supported by the finding that information-seeking behaviour characterizes Internet use (while Facebook, e.g., is mainly used for social networking and is less related to purposeful gathering of political information). Thus, while Internet use is related to international media interest, social media seem to map onto - rather than drive - political activism.

Again, media choices seem to respond to both individual attributes as well as structural differences. Thus, the gap between online and offline population is expected to narrow in the future not only in response to wider dissemination of technology but also as a result of changes in structural and individual factors - i.e. education, economy and urbanism. This indicates that the current characteristics of new media audiences (which are often linked to political activism and participation) are likely to change and become less specific and identifiable. All of this may suggest that the effect of new media on political participation retains it potentiality of being a significant relationship but one
14. Although, some of these patterns (i.e. frequent news sharing and checking) might be partially due to the influence of technology on information consumption behaviour. 
that may simply facilitate or move in a coordinated rather than causal manner 1 . with the stronger - and seemingly generational - predictors.

As pointed out above, activists often develop common identities through 3 . similar cohort experience (see Aday et al. 2012). In conjunction with the 4 . findings here, this suggests a path forward by shifting analytical focus from 5 . medium to users as a means to better understand the role of new media. For 6 . example, scholars refer to a number of characteristics that distinguish Egyptian 7. activists (i.e. those who gathered at Tahrir Square in 2011) from the broader 8. population. First, activists are perceived to be more liberal, western-oriented 9 . and secular than the average Egyptian (see Lynch 2011). Second, their demo- 10. graphic structure is believed to be different; they are usually described as 11 . urban, highly educated, middle class and primarily young (see Ishani 2011). 12. Third, protesters are perceived to be Internet-savvy actors and social media 13. users (see above). It is often argued that the ability of such calibre to spark 14 . broad-based protests was limited in the past and has fundamentally changed 15 . with the spread of social media (Lynch 2011). Thus, while social media seem 16. to show up as a potential causal factor in several political upheavals around 17. the world, the people who predominantly use these media are also likely to be 18 . the ones predominantly participating in politics. 19.

Yet, while new media users share similar characteristics to activists, they 20. remain relatively advantaged compared to the general population. As but 21 . one example, about $45 \%$ of the population of Egypt lives in urban areas, with 22 . over 19 million in Greater Cairo. Nearly three-fifths of the Cairo population 23. is under 30 years old (see Lim 2012), and more than 64\% of the household 24 . in Cairo have Internet (Dennis et al. 2013). This potentially corresponds with 25. findings from earlier research, drawing upon the Pew Research Centre Global 26. Attitudes Project survey in 2010, which showed social media users in Egypt 27. are slightly more positive in their evaluations of the performance of the econ- 28 . omy and more hopeful in their expectations about the future direction of their 29 . country than the general population (see Norris 2012).

Although analytically descriptive, this analysis has investigated the link 31 . between social demographics and individual media choices and compared 32 . 'profiles' of the 'average user' of different media. We then looked into how 33. citizens find information about their local and larger worlds. Our aim has 34 . been to map profiles of media consumption patterns and avoid missing 35 . details that may better inform the debate. However, this analysis has taken 36 . this approach for the following reason. We want to highlight the distinguish- 37. ing characteristics of both the media choices that are made and the attributes 38 . of the media choosers. This is important and often overlooked in the stam- 39 . pede to more sophisticated analysis. It gives us an opportunity to interro- 40 . gate the landscape of media choices from the perspective of media behaviour 41 . approaches as well as the technological determinist approach. Doing so, we 42 . force these data and this analysis into the 'new media' debate by examin- 43 . ing the relationship between traditional and new media use patterns, media 44 . use intentions (i.e. 'information-seeking behaviour') and ultimately, who is 45 . making these choices.

\section{ACKNOWLEDGEMENT}

The authors would like to thank the Broadcasting Board of Governance (BBG) 50 . and the BBC for making data available for this research and the Reuters 51. Institute (RISJ) for assistance on this matter. 
1.

3.

4.

5.

6.

7.

8.

9.

10.

11.

12.

13.

14.

15.

16.

17.

18.

19.

20.

21.

22.

23.

24.

25.

26.

27.

28.

29.

30.

31.

32.

33.

34.

35.

36.

37.

38.

39.

40.

41.

42.

43.

44.

45.

46.

47.

48.

49.

50.

51.

52.

\section{REFERENCES}

Abdulla, Rasha (2007), The Internet in the Arab World: Egypt and Beyond, New York: Peter Lang Publishing.

Aday, Sean, Farrell, Henry, Freelon, Deen, Lynch, Marc and Sides, John (2012), New Media and Conflict After the Arab Spring, Washington: US Institute for Peace, https://www.usip.org/sites/default/files/PW80.pdf. Accessed 1 November 2013.

Anderson, Lisa (2011), 'Demystifying the Arab Spring: Parsing the differences between Tunisia, Egypt, and Libya', Foreign Affairs, 90:4, pp. 2-7.

Dubai Press Club (2012), Arab Media Outlook 2011-2015, Dubai: Dubai Press Club, http://www.mearketing.com/download/ArabMedia2015.pdf.

Mourtada, Racha, Salem, Fadi and Alshaer, Sarah (2013), Arab Social Media Report, 5th ed., Dubai: Dubai School of Government, http://www.arabsocialmediareport.com/News/description.aspx?NewsID=12\&PriMenuID =15 \&mnu=Pri. Accessed 1 March 2014.

Aouragh, Miriyam and Alexander, Anne (2011), 'The Egyptian experience: Sense and nonsense of the internet revolution', International Journal of Communication, 5, pp. 1344-58.

Baker, Andy, Ames, Barry and Renno, Lucio R. (2006), 'Social context and campaign volatility in new democracies: Networks and neighborhoods in Brazil's 2002 elections', American Journal of Political Science, 50:2, pp. 382-99.

Ball-Rokeach, Sandra and DeFleur, Melvin (1976), 'A dependency model of mass media effects', Communications Research, 3:1, pp. 3-21.

Brym, Robert, Godbout, Melissa, Hoffbauer, Andreas, Menard, Gabe and Hui Zhang, Tony (2014), 'Social media in the 2011 Egyptian uprising', British Journal of Sociology, 65:2, pp. 266-92.

Comunello, Francesca and Anzera, Giuseppe (2012), 'Will the revolution be tweeted? A conceptual framework for understanding the social media and the Arab Spring', Islam and Christian-Muslim Relations, 23:4, pp. 453-70.

Cottle, Simon (2011), 'Media and the Arab uprisings of 2011: Research notes', Journalism, 12:5, pp. 647-59.

Dajani, Nabil (2012), ‘Technology cannot a revolution make: Nas-book not Facebook', Arab Media and Society, 15, http://www.arabmediasociety. com/?article=782. Accessed 1 March 2014.

Dennis, Everette, Martin, Justin D. and Wood, Robb (2013), 'Media use in the middle east: An eight-nation survey. North-Western University in Qatar', http://menamediasurvey.northwestern.edu/\#. Accessed 1 June 2014.

Dubai School of Government (2013), The Arab World Online: Trends in Internet Usage in the Arab Region, Dubai: Dubai School of Government, http:// archives.dimed.gouv.fr/sites/dimed.gouv.fr/files/asmr_-_the_arab_world_ online_trends_in_internet_usage_in_the_arab_region_-_avril_2013.pdf. Accessed 1 March 2014.

Hellyer, H. A. (2012), 'Violence and the Egyptian military', Foreign Policy, 13 January, http://mideast.foreignpolicy.com/posts/2012/01/13/violence_and_ the_egyptian_military. Accessed 1 March 2014.

Howard, Philip and Parks, Malcolm (2012), 'Social media and political change: Capacity, constraint, and consequence', Journal of Communication, 62:2, pp. 359-62.

Ishani, Maryam (2011), 'The hopeful network', Foreign Policy, 7 February, http://www.foreignpolicy.com/articles/2011/02/07/the_hopeful_network. Accessed 1 March 2014. 
Kavanaugh, Andrea, Hassan, Riham, Elmongui, Hicham G., Magdy, Mohamed, 1. Sheetz1, Steven, Yang, Seungwon, Fox, Edward and Shoemaker, Donald 2. (2012), 'Between a rock and a cell phone: Communication and informa- 3. tion technology use during the 2011 Egyptian uprising', Proceedings of the 4. 9th International ISCRAM Conference, ISCRAM: Vancouver, Canada, 22-25 5. April, http://www.iscramlive.org/ISCRAM2012/proceedings/185.pdf. 6. Accessed 1 June 2014.

Khamis, Sahar, Gold, Paul B. and Vaughn, Katherine (2012), 'Beyond Egypt's 8. "Facebook revolution" and Syria's"YouTube uprising": Comparing political 9. contexts, actors and communication strategies', Arab Media and Society, 15, 10. http://www.arabmediasociety.com/?article=791. Accessed 1 March 2014.11.

Lim, Merlyna (2012), 'Clicks, cabs, and coffee houses: Social media and oppo- 12. sitional movements in Egypt, 2004-2011', Journal of Communication, 62:2, 13. pp. 231-48. 14

Loveless, Matthew (2008), 'Media dependency: Mass media as sources of 15. information in democratizing countries', Democratization, 15:1, pp. 162-83. 16.

Lynch, Marc (2011), 'After Egypt: The limits and promise of online challenges 17. to the authoritarian Arab state', Perspectives on Politics, 9:2, pp. 301-10. 18.

Norris, Pippa (2012), 'The impact of social media on the Arab uprisings: The 19. Facebook, Twitter, and YouTube revolutions?', Advancing Comparative 20. Political Communication Research: New Frameworks, Designs and Data, ECPR 21. Joint Workshops, Antwerp, Belgium: European Consortium for Political 22. Research (ECPR), 10-15 April.

Papic, Marko and Noonan, Sean (2011), 'Social media as a tool for 24. protest', Stratfor global intelligence, 3 February, http://www.stratfor.com/ 25. weekly/20110202-social-media-tool-protest. Accessed 1 September 2017. 26.

Sakr, Naomi (2002), Satellite Realms: Transnational Television, Globalization and 27. the Middle East, London: I. B. Tauris.

Schmitt-Beck, Rüdiger (2004), 'Political communication effects: The impact of 29 . mass media and personal converssations on voting', in Frank Esser and 30. Barbara Pfetsch (eds), Comparing Political Communication: Theories, Cases, 31. and Challenges, Cambridge: Cambridge University Press, pp. 293-322. 32.

Wolfsfeld, Gadi, Segev, Elad and Sheafer, Tamir (2013), 'Social media and the 33. Arab Spring: Politics comes first', International Journal of Press/Politics, 18:2, 34. pp. $115-37$.

\section{SUGGESTED CITATION}

Jebril, N. and Loveless, M. (2017), 'Media audiences and media consumption during political transitions: The case of Egypt', Interactions: Studies in Communication \& Culture, 8:2\&3, pp. 151-167, doi: 10.1386/iscc.8.2-3.151_1

\section{CONTRIBUTOR DETAILS}

Nael Jebril is Senior Lecturer in Journalism and programme leader of the MA in Media and Communication at Bournemouth University. His research interests include media and democratization, audience studies, political communication and the Middle East. He is former academic Fellow in Media and Democracy at the Reuters Institute and the Politics Department at Oxford University and a co-recipient of the 2016 Goldsmith Book Prize by John F. Kennedy School of Government. He is currently a Fellow of the UK Higher Education Academy. 
1. Contact: Faculty of Media and Communication, School of Journalism, English

2. and Communication, Bournemouth University, Fern Barrow, Poole, Dorset,

3. BH12 5BB, United Kingdom.

4. E-mail: njebril@bournemouth.ac.uk

5.

6. Matthew Loveless has published several articles on the role of mass media in

7. the process of political socialization in democratizing countries (Comparative

8. Politics, Studies in Comparative International Development, Democratization and

9. the International Journal of Communication) and co-authored a state of the

10. discipline for the Reuters Institute at Oxford (with N. Jebril and V. Štětka). His

11. empirical work contributed to an individual-level understanding of demo-

12. cratic socialization via mass media in Eastern Europe. More recent projects

13. confront the role of media in countries that are transitioning, if not specifically

14. to democracy. He is currently a Jean Monnet Fellow at the Robert Schuman

15. Centre for Advanced Studies at the European University Institute (Italy).

16. Contact: Center for Research and Social Progress, Localitá i Bondini 4, 29028

18. Ponte dell'Olio (Piacenza), Italy.

19. E-mail: matthew.loveless@cersp.org

20. Nael Jebril and Matthew Loveless have asserted their right under the 21. Copyright, Designs and Patents Act, 1988, to be identified as the authors of 22. this work in the format that was submitted to Intellect Ltd.

23.

24.

25.

26.

27.

28.

29.

30.

31.

32.

33.

34.

35.

36.

37.

38.

39.

40.

41.

42.

43.

44.

45.

46.

47.

48.

49.

50.

51.

52. 